\title{
Sólo así: por una agenda ciudadana independiente*
}

* Castañeda, Jorge G., Sólo así: por una agenda ciudadana independiente, Penguin Random House, México, 2016, 86 pp.

Tla-Melaua, revista de Ciencias Sociales. Facultad de Derecho y Ciencias Sociales. Benemérita Universidad Autónoma de Puebla, México / Issn: 1870-6916 / Nueva Época, año 12, núm. 44, abril-septiembre 2018, pp. 276-282. 
La importancia de reseñar el libro de Jorge Castañeda se debe a varias razones. La primera, la actualidad que comporta el tema de las candidaturas independientes en el caso mexicano, a raíz de la reforma política electoral de agosto de 2012 y los triunfos independientes en los estado de Guanajuato, Nuevo León, Sinaloa y Jalisco durante las elecciones de 2015. Ello convirtió las candidaturas independientes en un nuevo fenómeno político, al que ha dado seguimiento lo mismo la prensa nacional que la internacional; ha sido también objeto de discusión entre intelectuales y activistas políticos. La segunda, se trata de la primera agenda política ciudadana, no partidista, que ofrece el núcleo básico mínimo de temas que necesariamente deberá abanderar una candidatura independiente rumbo a las elecciones presidenciales del 2018. Esta agenda menciona cuáles son las principales problemáticas que enfrenta México y la necesidad de impulsar una candidatura independiente que logre solucionarlos. Tercera, el autor, Jorge Castañeda, jugó un papel trascendental para el reconocimiento constitucional de esta nueva modalidad de candidaturas, pues en el 2007 demandó al estado mexicano ante la Comisión Interamericana de Derechos Humanos por habérsele negado el derecho a participar como candidato independiente en las elecciones presidenciales de julio de 2006. De esta manera, se estableció un precedente en la lucha por la ampliación de los derechos políticos en México, particular el derecho a ser votado.

La estructura del libro es sencilla. El mismo autor reconoce que se trata de un opúsculo o pequeña obra, cuyo tema central es la agenda de una candidatura independiente, así como los mecanismos que se deberán poner en marcha para lograr una candidatura fuerte hacia las elecciones de 2018. El opúsculo consta de tres capítulos, cada uno con sus partes. Estos son "Eyeless in Los Pinos: Un Sexenio de Tres años", "Una agenda ciudadana" y "Sólo así: Por una candidatura ciudadana independiente". El segundo capítulo se divide en seis partes: impunidad y derechos humanos, impunidad y corrupción, la partidocracia y sus dineros, la segunda vuelta electoral, en defensa del consumidor y una cuarta generación de derechos humanos. El tercer capítulo se estructura como sigue: los pros de una candidatura independiente, los supuestos contras de las candidaturas independientes, ¿Candidatura única? ¿Cómo? Y Los astros de 2018.

\footnotetext{
* Profesor investigador en la Facultad de Derecho y Ciencias Sociales de la Benemérita Universidad Autónoma de Puebla, México. (oscar.lagunes@correo.buap.mx) orcid.org/0000-0002-1449-8431
} 
El pequeño ensayo busca, en palabras de Castañeda, "socializar" el tripié": diagnóstico/agenda/candidatura (p. 12). En primer lugar un diagnóstico de la situación actual en que se encuentra el país, particularmente de los tres primeros años del gobierno de Enrique Peña Nieto (EPN). Segundo, enlista cuáles deben ser los temas centrales de una agenda ciudadana con miras al 2018. Tercero, hace una apología de las candidaturas independientes, señalando los argumentos en contra y los argumentos a favor de las mismas; analiza, además, la conveniencia de una candidatura única en vez de muchas. Nuestro autor dice que el gobierno de Peña intentó recuperar la rectoría del Estado, a la vieja usanza del PRI, mediante tres pactos.

El primero es el Pacto por México, en el que las tres principales fuerzas políticas del país (PRI, PAN, PRD) se sentaron a negociar las reformas que modificaron sustancialmente la Constitución: la fiscal, la educativa y la energética. Sin embargo, dichas reformas sumadas a acontecimientos como Ayotzinapa, Malinalco, el escándalo de la Casa Blanca, la fuga del Chapo Guzmán, entre otros, acabarían con la aparente popularidad del gobierno peñista y sumergirían al país en una de las más severas crisis de derechos humanos y corrupción de la que se tenga memoria. Las diferencias en los términos en que se planteó la reforma energética dividiría la izquierda perredista en dos partes, junto a su electorado, dando origen a Morena y al liderazgo de Andrés Manuel López Obrador (AMLO).

El segundo pacto es el que, supone el autor, se dio entre Felipe Calderón Hinojosa y EPN, presumiblemente desde noviembre de 2012 o quizás previo a las elecciones de julio de 2012. "Calderón y Peña Nieto llegaron a un entendimiento tácito, blindado por la omertá, o tal vez explícito, pero silencioso, que le puede haber aportado ventajas a ambos pero poco al país" (p. 19). Este acuerdo consistiría en que Calderón debilitaría la candidatura de la panista Josefina Vázquez Mota en favor del priista Peña y en contra del aún perredista AMLO. A cambio, Peña eximiría a Calderón y a su equipo de las atrocidades perpetradas durante ese sexenio. "Calderón garantizó los votos de sus senadores a favor de las reformas de Peña Nieto" (p. 19), en concreto, la reforma energética, sin "exigir grandes concesiones a cambio en materia de reforma política" (p. 20). El nuevo gobierno sería tapadera del anterior, pero el legado de Peña Nieto sería la "corrupción y violaciones a los derechos humanos" (Ibíd.). No obstante, se dividió el panismo y Calderón dejó de ser popular en su propio partido, e incluso, llegó a ser repudiado por el propio Gustavo Madero, presidente y líder del PAN. El objetivo del gobierno peñista era formar una coalición con el blanquiazul, para formar un frente común contra López Obrador quien tenía el 30 por ciento de las preferencias del electorado. Así se validarían las acusaciones del AMLO al denominar a ambos partidos como el PRIAN.

Un tercer pacto es el que formó EPN con el Estado de México y su pequeño grupo de colaboradores, cuates priistas, la mayoría procedente de 
ese estado y de Hidalgo: Ruiz Esparza, Beltrones, César Camacho, Osorio, Videgaray y Nuño, Gamboa, Chuayffet, Murillo Karam. Personas cortadas con la misma tijera y poco aptas para romper los sagrados compromisos del priismo de antaño. Nuestro autor resume los sexenios de Calderón y Peña Nieto del modo siguiente: "Mientras siga la guerra, se violan los derechos humanos. Mientras se violen los derechos humanos sin consecuencia alguna para los responsables [...], se consagra la impunidad. Al persistir la impunidad en este rubro, se extiende a otros" (p. 23).

El Pacto por México neutralizó a la oposición, a excepción de AMLO, impidiendo el funcionamiento del "incipiente sistema mexicano" de pesos y contrapesos (checks and balances) (pp. 22-23). Las elecciones del 6 de junio de 2015 confirmaron el hartazgo ciudadano respecto a los partidos políticos. En ellas pudo observarse el protagonismo que jugaron los jóvenes votantes de mayor nivel educativo, miembros de una nueva clase media emergente, donde hubo candidaturas independientes. En donde no, los ciudadanos optaron por emitir su voto en contra de los partidos salientes, como sucedió en Sonora, Guerrero y Michoacán. "Los votantes abandonaron en manada a los tres grandes partidos, asimilados a la partidocracia, entregándoles un porcentaje mayor que nunca de la votación total. A pesar de su mayoría en la Cámara, el partido del gobierno de Peña Nieto obtuvo 29\% del voto, su peor resultado en la historia, salvo Roberto Madrazo en 2006” (p. 25).

A pesar de estos resultados, no se conoce con certeza en qué niveles se encuentre el cansancio ciudadano hacia los partidos políticos, la clase política y las instituciones del Estado. Lo que sí puede hacerse es construir una agenda ciudadana en "tres posibles avenidas de acción robusta de la sociedad civil", 1) que haga converger todo el esfuerzo hacia las candidaturas sin partido; 2) que se haga hacia el conjunto de partidos interpelándolos y exigiendo a sus candidatos propuestas específicas a las problemáticas nucleares de la sociedad; 3) que una parte de la sociedad civil organizada converja en una candidatura partidista, la cual tomaría una parte de la agenda a cambio del apoyo ciudadano. Este es el caso de AMLO que forma parte de la partidocracia mexicana y que podría colocarse en lugar del outsider, "y atraer a sectores enfadados con el sistema actual y a partidarios de varias causas ciudadanas" (p. 27).

Castañeda considera demagógico el discurso de que el origen común de los males que padece nuestro país sea la desigualdad y la pobreza. Más bien, señala el autor, que todas nuestras desgracias provienen de "la impunidad, la corrupción y las violaciones a los derechos humanos [que] son consustanciales al sistema mexicano" (p. 29). En esa misma tónica argumentativa afirma que la culpa es del capitalismo rampante de corte neoliberal, pues el "saqueo del Estado mexicano efectuado desde épocas remotas por un capitalismo depredador nacido dentro de ese Estado ha contribuido mucho a la desigualdad mexicana, superior a la de otros países 
en la región" (pp. 29-30). Por esto es necesario acabar con la impunidad, castigando a los culpables de robar los recursos del país y de violar los derechos humanos. Es preciso que se haga justicia a las víctimas edificando un Estado de Derecho en el siglo XXI.

No se puede eliminar la corrupción ni acabar con las violaciones a los derechos humanos en México, si no se establece un sistema de justicia en el que impere la ley y se aplique a todos por igual. Por increíble que pueda parecer, todavía "en algunos ámbitos, los derechos humanos se contemplan como una distracción ante asuntos más importantes, o peor aún, como un obstáculo ante la necesaria lucha contra el crimen organizado, la inseguridad y las drogas" (p. 33). En México se confía en las instituciones, locales o internaciones, de derechos humanos, pues se asocia el término "derechos humanos" con cuestiones positivas. La defensa de dichos derechos se había afianzado a partir de la segunda mitad del sexenio de Ernesto Zedillo hasta finalizar la gestión de Fox, con la llegada de la democracia representativa en México. Sin embargo, el declive comenzó con Calderón (guerra contra el narco) y alcanzó su zenit con el gobierno de Peña (Ayotzinapa), junto a otras violaciones graves a los derechos humanos. Lo anterior terminó por hundir al país en una grave crisis de derechos humanos.

Por estas razones, la agenda de 2018 debe partir con la exigencia de respeto irrestricto a los derechos humanos. La impunidad tiene dos caras la violación a los derechos humanos y la corrupción. De acuerdo con Aguilar Camín, entre el 2000 y 2013 hubo en México 41 gobernadores acusados de corrupción en la prensa, pero sólo 16 de ellos fueron investigados y 4 de ellos detenidos. En cambio, en este mismo lapso de tiempo 9 gobernadores estadounidenses fueron acusados de corrupción: los nueve fueron investigados y todos detenidos. La impunidad "solo alimenta la irritación" (p. 37). No basta con sacar al PRI de Los Pinos, como sucedió en el 2000. Fox terminó negociando con la partidocracia y Calderón hizo lo mismo. "Pegarle a la corrupción y detener el asalto al Estado mexicano implicaba romper con la clase política, con las complicidades y recompensas existentes, en los tres poderes y en los tres niveles de gobierno" (p. 39). Es importantes que se establezcan medidas para suprimir la corrupción desde el nivel municipal: contralorías, testigos sociales de licitaciones, etc., porque actualmente "el Ejecutivo combate la corrupción en el Ejecutivo" (p. 40), lo que equivale a no combatir nada. Por lo mismo, es urgente la creación de una Contraloría totalmente autónoma y colegiada, propuesta por el presidente y ratificada por el Congreso, que tenga la capacidad de ejercer acción penal con su propio equipo de investigadores y con la capacidad de abrir el sigilo bancario; además, que exija a todo funcionario público su declaración 3x3 (patrimonial, fiscal y de conflicto de interés). No hay mejor forma de combatir la corrupción que mediante la transparencia. Una campaña para el 2018, tendrá que contemplar una 
cruzada anti-corrupción y ésta sólo podrá ser realizada por candidaturas independientes.

La corrupción resulta del vínculo entre el dinero y los partidos políticos. En parte, tiene su raíz en las grandes sumas de dinero legal público que el Estado destina a los partidos políticos a través del Instituto Nacional Electoral (INE) y al dinero ilegal privado que fluye entre los partidos para costear sus campañas. Esto hace que las alecciones en México sean las más caras del mundo. Ello requiere reducir el financiamiento público de los partidos e incrementar la cuota de recursos privados de origen lícito. También se requiere quitar todas las trabas legales a los candidatos independientes para que compitan en igualdad de condiciones con los partidos políticos (p. 70). Tienen que autorizarse a los partidos espacios en televisión más prolongados con contenido sustantivo, en vez de los actuales espacios de 30 segundos "embrutecedores" y organizar debates entre todos los candidatos desde el inicio de las elecciones. Hace falta también "eliminar la prohibición de las campañas negativas", pues "el precio de la mentira debe ser el costo de ser puesto en evidencia. Para lo demás, debe regir la legislación contra las calumnias, la difamación y el libelo" (p. 49). Es deseable que se agilice la creación de nuevos partidos políticos y que se aumente de 3 a 5 el porcentaje de los votos emitidos para que éstos no pierdan su registro: "debe volverse más fácil crear un partido y más difícil conservarlo" (p. 48). Los candidatos y dirigentes de partido tienen que ser objeto de responsabilidad penal por violar la legislación electoral y no sólo por asuntos relaciones con el gasto y el financiamiento de las campañas políticas. Hasta son risibles las penalidades aplicables a quienes violentan las leyes electorales.

En las elecciones de 2018 existe el peligro de la "pulverización del voto presidencial" (p. 49), particularmente si no se logran unificar las candidaturas independientes, y que el Titular del Ejecutivo Federal no cuente con mayoría en las Cámaras, como de hecho ha sucedido desde la segunda mitad del sexenio de Zedillo (Lujambio, 2001: 252). Para ello se necesita instaurar la segunda vuelta electoral (también propuesta por el PAN y el PRD), para asegurar al que gane un porcentaje del $50+1$ de los sufragios en la contienda presidencial en vez del 25 o 28 por ciento que pudiera obtener. Otro tema de la agenda independiente es la defensa del consumidor frente a los malos servicios que prestan las empresas y la creación de una cuarta generación de derechos humanos, a saber, los derechos de las minorías excluidas: la despenalización del aborto, el matrimonio entre personas del mismo sexo (permitidos en el DF y en otros estados) y la legalización de la marihuana.

Se ha dicho que desde 1994 al 2000 los mexicanos eligen de manera libre a sus gobernantes. Sin embargo, "sólo podíamos optar en libertad entre las fotos en la boleta", pero "no podíamos incidir en quiénes salían en la foto" (p. 57). En el 2018, por primera vez en la historia del México 
contemporáneo, podremos escoger entre candidatos de partidos o sin partido, como logro conseguido por la lucha de varios abogados y de políticos, como Manuel Clouthier. En las boletas electorales figurarán una o varias candidaturas independientes. Los pros de este tipo de candidatura es que gane o pierdan "puede sacudir a la clase política, $[\ldots]$, obligar a una reforma político-electoral y a reconfigurar el sistema de partidos, y a devolverle la confianza a la población en las elecciones, en las instituciones y en la política en general" (p. 59). A parte, sólo una candidatura independiente puede seguir la agenda aquí trazada, pues es "nula la posibilidad de que un candidato del PRI denuncie la corrupción o las violaciones de los derechos humanos bajo Peña Nieto, o que el del PAN "rompa con los mismos vicios en el gobierno de Calderón, o de que uno del PRD denuncie lo sucedido en el DF durante los últimos dieciocho años" (p. 60).

Sin negar el valor que representa la propuesta pública de una agenda independiente, que dicho sea de paso, ningún candidato del pasado o del presente lo había hecho, el contenido de libro tiene algunas deficiencias como todo trabajo humano: algunas partes no son muy claras y otras más parecen ser contradictorias. Por poner un ejemplo, el autor hace una defensa de las candidaturas independientes en toda su obra, pero en una parte de la misma dice "no sé qué sea mejor: un presidente de partido sin mayoría o un presidente sin partido" (p. 65). No obstante, la virtud que tiene el texto-agenda es propiciar el debate público de los grandes problemas de México, para ser luego enriquecida con las aportaciones de los mejores argumentos. 